\title{
Correction: A Cardiopulmonary Monitoring System for Patient Transport Within Hospitals Using Mobile Internet of Things Technology: Observational Validation Study
}

Jang Ho Lee ${ }^{1}$, MD; Yu Rang Park ${ }^{2}$, PhD; Solbi Kweon ${ }^{2}$, MS; Seulgi Kim ${ }^{1}$, MS; Wonjun Ji ${ }^{1}$, MD; Chang-Min Choi ${ }^{1,3}$, $\mathrm{MD}, \mathrm{PhD}$

${ }^{1}$ Department of Pulmonology and Critical Care Medicine, Asan Medical Center, University of Ulsan College of Medicine, Seoul, Republic of Korea

${ }^{2}$ Department of Biomedical System Informatics, Yonsei University College of Medicine, Seoul, Republic of Korea

${ }^{3}$ Department of Oncology, Asan Medical Center, University of Ulsan College of Medicine, Seoul, Republic of Korea

Corresponding Author:

Chang-Min Choi, MD, PhD

Department of Pulmonology and Critical Care Medicine

Asan Medical Center

University of Ulsan College of Medicine

88 Olympic-ro, 43-gil

Songpa-gu

Seoul, 05505

Republic of Korea

Phone: 82230105902

Email: ccm@amc.seoul.kr

\section{Related Article:}

Correction of: http://mhealth.jmir.org/2018/11/e12048/

(JMIR Mhealth Uhealth 2018;6(12):e12864) doi: 10.2196/12864

The authors of "A Cardiopulmonary Monitoring System for Patient Transport Within Hospitals Using Mobile Internet of Things Technology: Observational Validation Study" (JMIR Mhealth Uhealth 2018;6(11):e12048) wish to add their grant number to the Acknowledgments section.

Thus, the sentence "This study was supported by a grant from Korea Health Industry Development Institute" has been changed to "This study was supported by a grant from Korea Health Industry Development Institute (grant number HI17C0178)."

The correction will appear in the online version of the paper on the JMIR website on December 20, 2018, together with the publication of this correction notice. Because this was made after submission to PubMed, PubMed Central, and other full-text repositories, the corrected article also has been resubmitted to those repositories.

Edited by G Eysenbach; this is a non-peer-reviewed article. Submitted 19.11.18; accepted 28.11.18; published 21.12.18.

Please cite as:

Lee JH, Park YR, Kweon S, Kim S, Ji W, Choi CM

Correction: A Cardiopulmonary Monitoring System for Patient Transport Within Hospitals Using Mobile Internet of Things Technology:

Observational Validation Study

JMIR Mhealth Uhealth 2018;6(12):e12864

URL: http://mhealth.jmir.org/2018/12/e12864/

doi: $10.2196 / 12864$

PMID: $\underline{30578236}$

CJang Ho Lee, Yu Rang Park, Solbi Kweon, Seulgi Kim, Wonjun Ji, Chang-Min Choi. Originally published in JMIR Mhealth and Uhealth (http://mhealth.jmir.org), 21.12.2018. This is an open-access article distributed under the terms of the Creative Commons Attribution License (https://creativecommons.org/licenses/by/4.0/), which permits unrestricted use, distribution, and 
reproduction in any medium, provided the original work, first published in JMIR mhealth and uhealth, is properly cited. The complete bibliographic information, a link to the original publication on http://mhealth.jmir.org/, as well as this copyright and license information must be included. 